\title{
Green Roles of Human Resource Professionals
}

\section{Chathuskka B. S. Liyanapatabandi ${ }^{1} \&$ N. N. J. Nawaratne ${ }^{2}$}

1. PhD Candidate, Faculty of Graduate Studies, University of Colombo

2. Professor, Department of Human Resources Management, Faculty of Management \& Finance, University of Colombo

ABSTRACT
Environment sustainability (ES) has emerged as a key strategic
priority in organizations due to the significant attention on environmental
concerns. Employees are the main drivers of a sustainable corporate
environmental strategy, and as a key function that deals with employees,
Human Resource Management (HRM) has a vital role in adding value to
an organization in achieving ES goals. Emanating from a broader focus
on HRM, Green Human Resource Management (GHRM) specifically aims
to transform "normal" employees to "green" employees. GHRM is the
intersection of HRM and ES. However, despite the significant attention on
how GHRM can support ES, scholarly work on understanding the "green
role" of HR professionals is sparse. As per the extant literature, it is evident
that research conducted connecting GHRM, employee-green behavior,
HR professionals and ES is limited. This lack marks a range of theoretical
and empirical gaps in the field. One key gap is the absence of a theoretical
framework and typology of green roles for HR professionals. Against this
backdrop, this article introduces four green roles that HR professionals
can play in facilitating environmental sustainability. By doing so it makes a
theoretical contribution to broadening the existing literature on ES.
Environment Sustainability, Green Human Resource Management
(GHRM), Green Behavior, Role of HR professionals, Sustainability

Suggested Citation: Liyanapatabandi, C. B. S. \& Nawaratne, N.N.J. (2021). Green Roles of Human Resource Professionals. University of Colombo Review (New Series III), 2(2), 151 - 161.

(C) 2021 The Authors. This work is licenced under a Creative Commons Attribution 4.0 International Licence which permits unrestricted use, distribution, and reproduction in any medium, provided the original work is properly cited. 


\section{Introduction}

The escalation of environmental issues around the world has led organizations to embrace environmental practices at a rapid pace to become "green and competitive" (Jabbour et al., 2012). There is a gradual demand from stakeholders for organizations to be environmentally cautious (Boiral et al., 2015; Boiral et al., 2018). Treaties and agreements such as Copenhagen Climate Agreement in 2010, Bali Road Map in 2007, and Kyoto Protocol in 1997 provided significant reasons for organizations to recognize that environmental sustainability was strategic and important, and many initiated "go green" programs (Yong \& Yusoff, 2016). The role of HR in ES has become vital in this context, and as detailed by James and Stewart (1996), successful outcomes are subject to both the level of business experience/ understanding and environmental competency.

The intersection of ES and HR is identified as GHRM. GHRM is a subsection of HRM aimed at transforming "normal" employees into "green" employees to achieve the environmental goals of the organization and make an important contribution to environmental sustainability (Opatha \& Arulrajah, 2014). There are three main components to the definition: transforming employees, achieving environmental goals and make an important contribution. The role of a HR manager, according to available definitions, is a combination of GHRM and employee green behavior. Employee participation in GHRM practices will result in the efficient usage of resources. Reducing waste, being mindful of the usage of water, electricity and food, adapting life-styles to environmental friendly actions like carpooling, reusing, sharing and substituting plastic are behavioral changes that will improve the environmental sustainability outcomes of organizations.

According to Wehrmeyer (1996), the responsibility of HRM towards environment management includes facilitating, implementing and handling changes in the work process and the motivation of staff. Guiding line managers to encourage employees to support environment management (EM) activities is also a primary responsibility of HR professionals (Mandip, 2012; Renwick et al., 2008). Demonstrating a high degree of knowledge and understanding about the subject matters as well, as an EM supportive work attitude, personal motivation, and relationship building with line managers/colleagues are also expected of HR professionals (Renwick et al., 2008; Wehrmeyer,1996). Further, it is also important to recognize environmental leadership as a prerequisite for organizational greening (Boiral et al., 2018, Boiral et al., 2014, Ulrich 1998). As clearly evident in the literature, HR professionals are responsible for a highly complex role in GHRM.

Brundtland (1987, p.39) defined environment sustainability (ES) as meeting "the needs and aspirations of the present without compromising [on] the ability to meet those of the future". Ulrich et al. (2015) identified "sustainability" as one of the future challenges for HR which need continuous attention. ES as a sub section of Corporate Social Responsibility that requires the same level of attention by HR professionals. However, the role of HR in facilitating corporate sustainability is largely unexplored (De Stefano et al, 2017) although it has been identified as an integral part of promoting environmentally friendly functions in an organization (Mishra et al, 2014). One reason for this could be that HR and sustainability operate in silos (Harris \& Trigidga, 2012). The disconnect between HR and environment 
sustainability is evident in the extant literature. For instance, while studies (De Stefano et al., 2017; Harris \& Trigidga, 2012; Jackson, 2012; Rimanoczy \& Pearson, 2010) have been conducted on the role of HR in sustainability or environmental sustainability those on GHRM have failed to acknowledge the role of HR professionals. A primary reason for this could be the lack of attention towards identifying "the green roles" of HR professionals in implementing GHRM in the organization. The second reason could be that researchers focus more on the development of GHRM as a concept itself.

Ever since Srivastava (1994) called for organizations to consider disclosing corporate environmental activities seriously, there has been emergent research on the role of HR in sustainability. Since then, organizations have recognized and reported their environmental practices. However, while the operations and accounting fields have successfully determined their role and impact on environmental sustainability, HR has failed to identify the type of role it should perform (Harris \& Tregidga, 2012).

Yong and Yusoff (2016) conducted research on the strategic HR competencies required in adopting green HRM. This pioneering research contributed to an existing gap on green roles for HR professionals. However, the selected sample was limited to a few HR professionals causing adverse effect on the findings even though their research encouraged more studies on the same lines which included the role of HR. Harris and Tregidga (2012) investigated whether HR managers are strategic leaders or passive observers. This remarkable study revealed that HR managers demonstrated passive behavior in the organization but concern for the environment in their private lives.

GHRM processes and policies alone are insufficient for fostering a green workforce in organizations. HR managers play an important role in transforming green HR policy into practice. It is important, therefore, to understand how employees feel and think about their responsibility towards the environment rather than taking a problem-solving approach (Jackson, 2012). This suggests that HR professionals adopt a "hands-on" approach to GHRM rather than engaging in environmental activities which require behavioral changes. Examining how environmental territory intersects with HR is also important. Further, there can be implications for the recognition of HR as a strategic partner in the organization if HR fails to integrate with environment management successfully. Therefore, this article focuses on the research question: What are the green roles of HR professionals?

The following sections offer a literature review, framework and approach, and a discussion aimed at answering the above research question.

\section{Literature review}

The role of HR professionals is evolving with changes in the business world (Srivastava, 2000). Global competition, technological advancement, and environmental challenges are among the significant changes in the field. Building organizational capability to maximize its potential is one of the major challenges HR professionals must confront in the 21 st century (Srivastava, 2000). Therefore, continuous learning and adapting to deliver business requirements is a major challenge. The hardest of all is to ensure the quality of HR professionals (Ulrich, 1998). Therefore, understanding and acquiring new competencies is 
critical for the profession. This should be a mix of functional knowledge, leadership, strong self-concept, and personal competencies including self-awareness, self-management, relationship skills, and responsible decision-making.

There is an argument that HR professionals lack orientation and competencies in supporting organizational sustainability (Wirtenberg et al., 1997). This includes environmental sustainability (ES). Further, Harris and Tregidga (2012) states that HR practitioners have failed to identify environment sustainability as an important aspect to give attention to and for action. Consistency in aligning business strategy with HRM practices is an important aspect of successful performance (Harris \& Tregidga, 2012). In this context, it is important for HR to realign its practices to support the ES strategies of the organization. GHRM is the outcome of merging environment sustainability and HR. Academic and empirical work on GHRM is gradually increasing and the attention of scholars had been on developing the concept itself (Ahmad, 2015; Jackson et al, 2011; Mishra et al, 2014; Opatha \& Arulrajah, 2014; Yusoff et al., 2015), its determinants, (Obeidat et al., 2018; Ooi et al., 2017; Shen et al.,, 2018; Yong et al, 2019; Yusliza et al., 2017), it implementation (Chaudhary, 2019, Fayyazi et al., 2015; Haddock-Millar et al., 2016; Jabbour, 2011; Rani \& Mishra, 2014), and its outcomes (Bon and Jaaron, 2018; Jabbour \& Abid, 2015; Mousa et al., 2020; Ragas et al, 2016; Zaid et al, 2018). Research on the role of HR in GHRM has been limited and superficial.

The role of HR professionals is based on ten managerial roles which Mintzberg (1980) categorized under interpersonal, informational, and decisional. The main functions of HR such as recruitment and selection, performance appraisal, training and development, employee relations and compensation have developed separate sub-roles, given the different functionalities and unique skill sets required. As a result, organizations have HR specialists and generalists depending on their scope of work.

Wiley (1992) identified 14 roles categorized broadly as strategic, operational, and legal in research conducted on HR professionals in the US. Storey (1992) identified the HR managers' roles as "advisors", "handmaidens", "change makers", and "regulators" in a study of 15 UK organizations. Conner and Ulrich (1996) conducted a study to explore HR managers roles by using a sample of $256 \mathrm{HR}$ professionals, and introduced widely accepted typologies (Mammon, 2013) of HR roles such as strategic partner, administrative expert, employee champion, and change agent etc. Further, Ulrich et. al. (2012), based on research conducted, introduced six roles for an effective HR professional such as credible activist, strategic positioner, capability builders, change champion, HR innovators and integrators, and technology proponents.

Ulrich (2015) and Srivastava (2000) also recommended that the HR fraternity rethink and redesign the role of HR professionals to best suit its business environment. HR needs, therefore, to identify environment sustainability (ES) as a business priority and realign appropriately. ES should contribute to business rather than being thought of as a set of disconnected or isolated activities (Ulrich \& Brockbank, 2008). HR should be engaged in the decision-making and execution of policies and practices and policies to ensure the successful implementation of environmental sustainability (Harris \& Tregidga, 2012). 


\section{Framework and Approach}

The proposed model in this article, (Figure 1) for "green roles" for HR professionals draws on the leading model of HR roles developed by Ulrich (1996). According to Ulrich's model, four roles have emerged from the intersection of two factors: strategic focus/future or operations/ present, and people or process. The four quadrants identified are those of a strategic partner, a change agent, an administrative expert, and an employee champion.

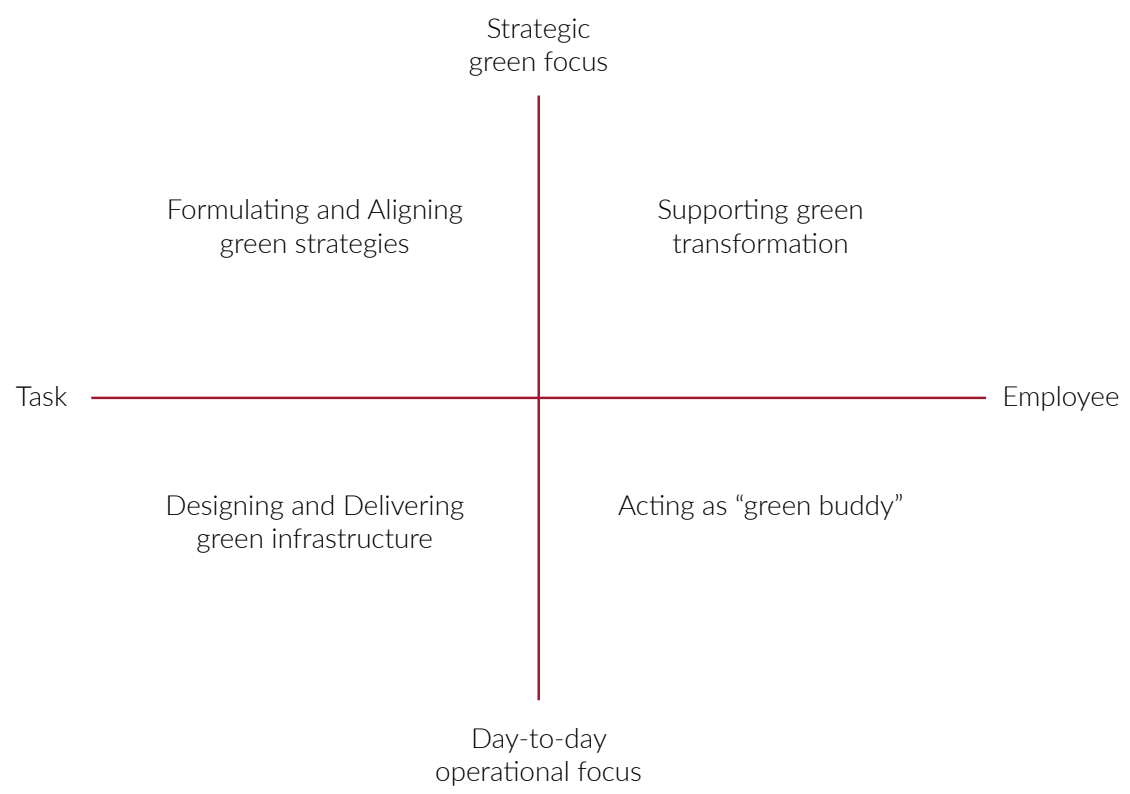

Figure 1

The 4 "green roles" of HR professionals.

The GHRM roles are directly associating with leadership orientation and strategic orientation of the HR professionals. Task oriented HR professionals are concerned primarily with achievement of the task; whereas employee oriented HR professionals are concerned with developing relationships. The contrast between task and employee captures the extent to which the orientation is towards the technical aspects of GHRM functions: recruitment, training and development, performance management, and compensation for designing and delivering green employee behavior, and orienting employees towards green behavior. The contrast between strategic green focus and day-to-day operational focus captures the extent to which HR considers a long-term green strategic approach to a day-to-day operational strategic approach when making decisions towards green transformational outcomes. Further, supporting green transformation and acting as a "green buddy" to employees can be considered a "soft" GHRM role, while formulating and aligning green strategies, and designing and delivering green infrastructure can be considered "hard" GHRM roles. 


\section{A Typology of Green Roles}

The role of formulating and aligning green strategies: this refers to developing GHRM strategies and linking them to environmental sustainability goals. This role requires HR professionals to assess the current status of environment sustainability, environmental sustainability strategies, identify how existing GHRM functions can support achieving green targets, and develop new strategies to align with environmental sustainability goals. GHRM functions recruitment, training and development, performance management and compensation to be assessed separately for suitable strategy formulation and alignment of environment sustainability.

The role of Supporting green transformation: the prime responsibility of HR is to support employees to transform as "green" employees in line with green strategies. Leidner (2018), found that eliciting green behavior of employees is not supported by sustainability advocates. There has to be an intervention by HR professionals as resistance comes with change. HR professionals should inspire trust and confidence in adapting to green initiatives. The hardest responsibility is changing organizational culture (Ulrich, 2007). Defining and clarifying the required change to build a green culture, communicating to employees the reasons for the need for attitudinal change, introducing green culture audits, and new ideas to support green culture are the areas requiring attention.

Designing and delivering green infrastructure: this results when there is alignment between tasks and operations. This entails formulating relevant green activities/practices for each HR function, and guiding line managers and employees on the efficient implementation of GHRM. HR professionals are already engaged in this area (Chaudhary, 2019). However, it has also been found that organizations are only partially successful in implementing HR practices which are fully aligned with environmental goals (Yong et al.,2019).

Acting as a "green buddy": this refers to supporting and motivating employees to do their best as a "green employee". It is the responsibility of HR professionals to ensure that employees are fully engaged and committed to organizational green goals. HR needs to take an approach where employees feel that HR professionals and employees are in a partnership, with trusted guidance from the former as an expert in GHRM. It is essential that HR professionals display their knowledge, skills, and attitude along with green behavior, and offer support to employees in professional as well as personal spheres towards building a sustainable organization.

\section{Discussion}

The goal of introducing a typology of green roles is to develop an answer to our research question: what are the green roles of HR professionals? The proposed model explained the type of green roles HR professionals need to adopt to support sustainable corporate environmental strategies. This is an original perspective in developing green roles because, by going beyond traditional HR roles, it broadened the model developed by Ulrich (1996). 
The role of HR in EM as detailed by James and Stewart (1996) is subject to the level of business experience, understanding, and environment competency. Despite growing attention on how HR can contribute to EM and its overall sustainability, it has been noted that the general attitude of HR professionals remains unsupportive (Guerci et al., 2019; Renwick et al., 2008). This shows that HR professionals are yet to be convinced of the important role they are required to undertake in promoting environmental sustainability. According to Harris and Tregidga (2012), HR professionals accepts that there is a role to play. However, the study revealed that the role is not considered strategic; not because it is not important, but because other core functions take priority over environmental functions.

Sustainable companies need to consider social and environmental impacts when making business decisions. In the U.S., $6 \%$ of HR professionals considers HR as undertaking a leadership role in defining and implementing sustainable strategies (Guerci et al., 2019). In the UK, some qualified HR professionals question the need to be involved in EM as they think there is a lot of hype about it than the real requirement (Renwick et al., 2008). A reason for this reluctance is that HR wants to be an "ally to the present economic system that is destroying the environment itself" (Hart \& Ahuja, 1996). Therefore, the focus of HR professionals in this domain is distorted. However, the facilitation of organizational culture towards GHRM practices would encourage employees to develop awareness of environmental consequences and the personal responsibilities towards the green behavior. Another barrier is that the support given by HR for EM is challenged as various implementation errors take place given that there are only a few who are competent in the field (Hitchcock and Willard, 2006).

Establishing green roles through a model would provide a detailed account of where and how HR professionals should act to support environmentally sustainable organizations. The lack of theoretical and empirical research on the roles of HR professionals in this area is the main reason for ambiguous approaches to green roles. Theoretically, environmental sustainability, GHRM, and employee green behavior are analyzed without connecting all three aspects. This is the main reason why HR professionals don't feel that their role in supporting environmental sustainability is important. The proposed framework will facilitate HR professionals to have a holistic approach towards GHRM with a clear purpose.

\section{Conclusion}

Re-defining the role of HR professionals and/ or designing a new role is important to ensure the successful implementation of GHRM in organizations. The main aim of the article was to develop a framework for such green roles. The new roles would connect HR professionals' responsibility for GHRM functions and employee green behavior. The implications of this are, firstly, that HR professional should assert a clear and active role in each of the quadrants mentioned. Secondly, they should develop necessary competencies to maintain expectations and performance. Thirdly, a wide acceptance of the HR green role among HR professionals should be encouraged. This article emphasizes four green roles of HR professionals. This is an important move for corporates in their journey towards sustainable futures. 


\section{Reference}

Ahmad, S. (2015). Green human resource management: Policies and practices. Cogent Business \& Management, 2(1), https://doi.org/10.1080/23311975.2015.1030817

Boiral, O., Raineri, N., \& Talbot, D. (2018). Managers' citizenship behaviors for the environment: a developmental perspective. Journal of Business Ethics, 149(2), 395-409.

Boiral, O., Talbot, D., \& Paille', P. (2015). Leading by example: A model of organizational citizenship behavior for the environment. Business Strategy and the Environment, 24(6), 532-550.

Bon, A. T., Zaid, A. A., \& Jaaron, A. (2018). Green human resource management, green supply chain management practices and sustainable performance. Proceedings of Industrial Engineering and Operations Management (IEOM),(Bandung, Indonesia) March (pp. 6-8).

Brockbank, W., \& Ulrich, D. (2008). HR competencies that make a difference: In J. Storey, P. Wright \& D Ulrich (Eds.), The Routledge companion to strategic human resource management (pp. 183197). Routledge.

Brundtland, G. H. (Ed.). (1987). Our common future: The World Commission on Environment and Development. Oxford, England: Oxford University Press.

Chaudhary, R. (2019). Green human resource management in Indian automobile industry. Journal of Global Responsibility, 10(2), 161-175.

Conner, J., \& Ulrich, D. (1996). Human resource roles: Creating value, not rhetoric. People and Strategy, 19(3), 38.

De Stefano, F., Bagdadli, S., \& Camuffo, A. (2018). The HR role in corporate social responsibility and sustainability: A boundary - shifting literature review. Human Resource Management, 57(2), 549-566.

Fayyazi, M., Shahbazmoradi, S., Afshar, Z., \& Shahbazmoradi, M. (2015). Investigating the barriers of the green human resource management implementation in oil industry. Management Science Letters, 5(1), 101-108.

Guerci, M., Decramer, A., Van Waeyenberg, T., \& Aust, I. (2019). Moving beyond the link between HRM and economic performance: A study on the individual reactions of HR managers and professionals to sustainable HRM. Journal of Business Ethics, 160(3), 783-800.

Haddock-Millar, J., Sanyal, C., \& Müller-Camen, M. (2016). Green human resource management: A comparative qualitative case study of a United States multinational corporation. The International Journal of Human Resource Management, 27(2), 192-211.

Harris, C., \& Tregidga, H. (2012). HR managers and environmental sustainability: strategic leaders or passive observers? The International Journal of Human Resource Management, 23(2), 236254.

Hart, S. L., \& Ahuja, G. (1996). Does it pay to be green? An empirical examination of the relationship between emission reduction and firm performance. Business strategy and the Environment, 5(1), 30-37. 
Hitchcock, D., \& Willard, M. (2006). The business guide to sustainability: Practical strategies and tools for organizations (2nd ed.), London, Routledge.

Jabbar, M. H., \& Abid, M. (2015). A study of green HR practices and its impact on environmental performance: A review. Management Research Report, 3(8), 142-154.

Jabbour, C. J. C. (2011). How green are HRM practices, organizational culture, learning and teamwork? A Brazilian study. Industrial and Commercial Training, 43(2), 98-105

Jabbour, C. J. C. (2013). Environmental training in organisations: From a literature review to a framework for future research. Resources, Conservation and Recycling, 74, 144-155.

Jabbour, C. J. C., Jabbour, A. B. L., Teixeira, A. A., \& Freitas, W. R. S. (2012). Environmental development in Brazilian companies: The role of human resource management. Environmental Development, 3, 137-147.

Jackson, S. E. (2012). Building empirical foundations to inform the future practice of environmental sustainability. Managing human resources for environmental sustainability, 416-432.

Jackson, S. E., Renwick, D. W., Jabbour, C. J., \& Muller-Camen, M. (2011). State-of-the-art and future directions for green human resource management: Introduction to the special issue. German Journal of Human Resource Management, 25(2), 99-116.

James, P., \& Stewart, S. (2017). The European environmental executive: technical specialist or corporate change agent? Greening people (pp. 143-161). Routledge.

Leidner, S., Baden, D., \& Ashleigh, M. J. (2019). Green (environmental) HRM: Aligning ideals with appropriate practices. Personnel Review 48(5), 1169-1185.

Mamman, A., \& Somantri, Y. (2014). What role do HR practitioners play in developing countries: an exploratory study in an Indonesian organization undergoing major transformation. The International Journal of Human Resource Management, 25(11), 1567-1591.

Mandip, G. (2012, January). Green HRM: People Management Commitment to Environmental Sustainability. Proceedings of 10th International Conference on Digital Strategies for Organizational Success, Retrieved from: http://dx.doi.org/10.2139/ssrn.3323800

Mintzberg, H. (1989). Mintzberg on management: Inside our strange world of organizations. New York: Simon and Schuster.

Mishra, R. K., Sarkar, S., \& Kiranmai, J. (2014). Green HRM: innovative approach in Indian public enterprises. World Review of Science, Technology and Sustainable Development, 11(1), 26-42.

Mousa, S.K. and Othman, M., (2020). The impact of green human resource management practices on sustainable performance in healthcare organisations: A conceptual framework. Journal of Cleaner Production, 243, Retrieved from: https://doi.org/10.1016/j.jclepro.2019.118595

Obeidat, S. M., Al Bakri, A. A., \& Elbanna, S. (2020). Leveraging “green” human resource practices to enable environmental and organizational performance: Evidence from the Qatari oil and gas industry. Journal of Business Ethics, 164(2), 371-388. 
Ooi, S. K., Amran, A., Goh, S., \& Nejati, M. (2017). Perceived importance and readiness of green HRM in Malaysian financial services industry. Global Business and Management Research, $9(4 s), 457-474$.

Opatha, H. H. P., \& Arulrajah, A. A. (2014). Green human resource management: Simplified general reflections. International Business Research, 7(8), 101-112.

Ragas, S. F. P., Tantay, F. M. A., Chua, L. J. C., \& Sunio, C. M. C. (2017). Green lifestyle moderates GHRM's impact on job performance. International Journal of Productivity and Performance Management, 66(7), 857-872.

Rani, S., \& Mishra, K. (2014). Green HRM: Practices and strategic implementation in the organizations. International Journal on Recent and Innovation Trends in Computing and Communication, 2(11), 3633-3639.

Renwick, D., Redman, T., \& Maguire, S. (2008). Green HRM: A review, process model, and research agenda. University of Sheffield Management School, 1, 1-46.

Rimanoczy, I., \& Pearson, T. (2010). Role of HR in the new world of sustainability. Industrial and Commercial Training, 42(1), 11-17.

Shen, J., Dumont, J., \& Deng, X. (2018). Employees' perceptions of green HRM and nongreen employee work outcomes: The social identity and stakeholder perspectives. Group \& Organization Management, 43(4), 594-622.

Shrivastava, P. (1994). Castrated environment: Greening organizational studies. Organization Studies, 15(5), 705-726.

Srivastava, K. B. (2000). Rethinking HR: Role of HR professionals in a changing business environment. Indian Journal of Industrial Relations, 35(4), 532-544.

Storey, J. (1992), Developments in the Management of Human Resources, Oxford: Blackwell.

Ulrich, D. (1996). Human resource champions: The next agenda for adding value and delivering results. Cambridge: Harvard Business Press.

Ulrich, D. (1998). A new mandate for human resources. Harvard Business Review, 76, 124-135.

Ulrich, D., \& Dulebohn, J. H. (2015). Are we there yet? What's next for HR? Human Resource Management Review, 25(2), 188-204.

Ulrich, D., Younger, J., Brockbank, W., \& Ulrich, M. D. (2013). The state of the HR profession. Human Resource Management, 52(3), 457-471.

Wehrmeyer, W. (1996). Greening people: Human resources and environmental management. Sheffield: Greenleaf.

Wiley, C. (1992), A Comprehensive View of Roles for Human Resource Managers in Industry Today, Industrial Management, 34(6), 27-29. 
Wirtenberg, J., Harmon, J., Russell, W. G., \& Fairfield, K. D. (2007). HR's role in building a sustainable enterprise: Insights from some of the world's best companies. People and Strategy, 30(1), 10-20.

Yong, J. Y., \& Mohd-Yusoff, Y. (2016). Studying the influence of strategic human resource competencies on the adoption of green human resource management practices. Industrial and Commercial Training, 48(8), 416-422.

Yong, J. Y., Yusliza, M. Y., \& Fawehinmi, O. O. (2019). Green human resource management: A systematic literature review from 2007 to 2019. Benchmarking: An International Journal, 27(7), 2005-2027.

Yusliza, M. Y., Othman, N. Z., \& Jabbour, C. J. C. (2017). Deciphering the implementation of green human resource management in an emerging economy. Journal of Management Development, $36(10), 1230-1246$.

Yusoff, Y. M., Ramayah, T., \& Othman, N. Z. (2015). Why examining adoption factors, HR role and attitude towards using E-HRM is the start-off in determining the successfulness of green HRM. Journal of Advanced Management Science, 3(4), 337-343.

Zaid, A. A., Jaaron, A. A., \& Bon, A. T. (2018). The impact of green human resource management and green supply chain management practices on sustainable performance: An empirical study. Journal of Cleaner Production, 204, 965-979. 